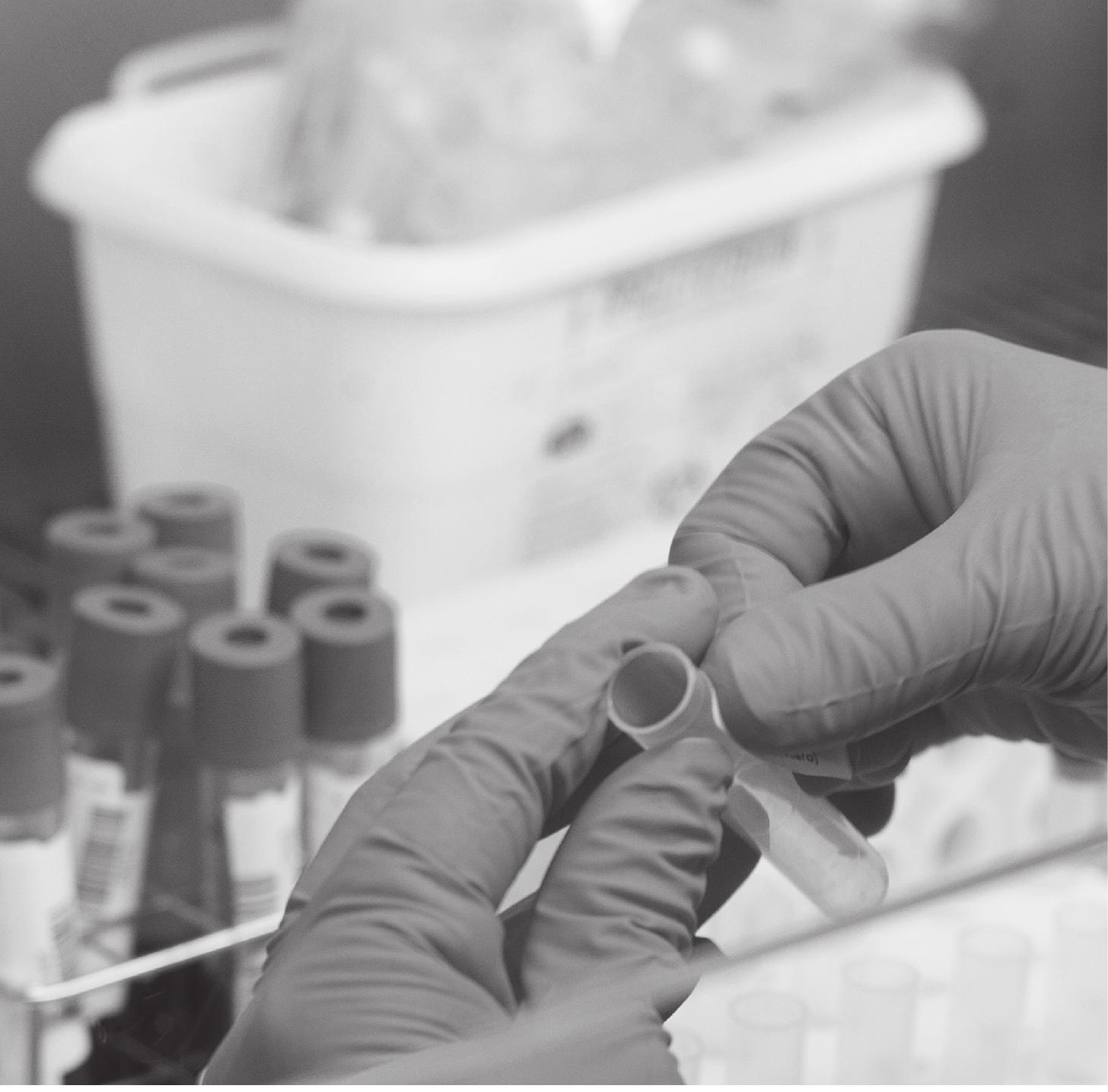

AIBR

Revista de Antropología Iberoamericana www.aibr.org Volumen 11

Número 3

Septiembre - Diciembre 2016 Pp. 341 - 362

Madrid: Antropólogos Iberoamericanos en Red. ISSN: 1695-9752

E-ISSN: 1578-9705
Del biopoder al cinepoder en los dispositivos de bioseguridad de la Unión Europea

Pedro Torrejón

Francisco Tirado

Enrique Baleriola

Marco Maureira

Universitat Autònoma de Barcelona

Recibido: 31.01.2016

Aceptado: 15.10.2016

DOI: 10.11156/aibr.110303 


\title{
RESUMEN ${ }^{1}$ :
}

En pleno siglo XXI, la biomedicina y la biotecnología se han convertido en dos características fundamentales del mundo en el que vivimos. Sin duda, el autor que más se ha trabajado para analizar las repercusiones políticas de estos avances ha sido Michel Foucault a partir de su concepción del biopoder y posteriormente Nikolas Rose al hablar de ethopolitica. Nuestra propuesta afirma que las ideas de ambos sobre lo biótico se engloban en un dispositivo de gestión y administración mayor que lo convierte en una trayectoria o flujo de movimiento, al que denominamos cinepoder. Mediante un estudio de caso de los dispositivos de bioseguridad de la Unión Europea, ilustraremos las características del cinepoder y sus implicaciones sobre el bios.

PALABRAS CLAVE:

Cinepoder, bioseguridad, epidemias, Foucault.

\section{FROM BIOPOWER TO KINEPOWER IN THE DISPOSITIVES OF BIOSECURITY OF THE EUROPEAN UNION}

\begin{abstract}
:
In the beginning of the $\mathrm{XXI}^{\text {th }}$ Century, biomedicine and biotechnology have become two defining characteristics of our every day. Doubtless, one of the main authors referenced in the analysis of this impact has been Michel Foucault and his notion of biopower. More recently the Nikolas Rose's idea of ethopolitics has acquired a similar relevance and has received a substantial attention in Social Sciences. Our paper puts forward that the proposals of both about life should be included in a device of management and government that turns the biotic into a trajectory or flow of movement. We have called this new dispositive kinepower. We will illustrate the characteristics of this dispositive through a case study focused on the European Union practices and discourse about biosecurity.
\end{abstract}

KEY WORDS:

Cine-power, biosecurity, epidemics, Foucault.

1. Este trabajo se ha realizado en el marco del programa de doctorado de la Universitat Autònoma de Barcelona. Simultáneamente, el trabajo se enmarca en el proyecto de investigación «Salud y tecnociencia. La participación ciudadana en los procesos de apropiación social del conocimiento y de diseño tecnológico", financiado por el Ministerio de Economía y Competitividad del gobierno de España (CSO2014-59136-P). 


\section{Introducción}

En las dos últimas décadas ha aparecido un importante volumen de literatura que explora el impacto de la biomedicina y la biotecnología en nuestra vida cotidiana a partir del prisma que ofrece la gubernamentalidad (Caduff, 2015; Collier y Lakoff, 2014; Hinchliffe y Lavau, 2013; Wahlberg y Rose, 2015). Este tipo de trabajos tiene como punto de partida las propuestas de Michel Foucault sobre la noción de biopoder (en sus dos formatos, anatomopolítica y biopolítica), y se despliegan como herramienta analítica para examinar el tipo de racionalidades que conforman las relaciones de dominación, resistencia y constitución de subjetividad que pueblan nuestro día a día.

Probablemente, la más importante de todas ellas sea la de Nikolas Rose (1989, 1996, 2006 y 2013). Este autor sostiene que las transformaciones que ha experimentado la biología molecular, junto con la genética y la bioquímica, han transformado nuestra actualidad. Por un lado, se han convertido en las ciencias matrices desde las que se piensa todo el juego de verdades y normas que se producen para regir nuestra vida en sus más íntimos detalles ${ }^{2}$. En segundo lugar, estarían abriendo nuevos mercados y dimensiones económicas. Por último, conformarían nuevas racionalidades de poder que tornarían obsoletas las discutidas por el propio Michel Foucault. En ese sentido, Rose ha postulado que la racionalidad biopolítica está dejando paso a una nueva, que él denomina ethopolítica; es decir, una racionalidad en que se produce un entrecruzamiento entre las técnicas de gobierno y autogobierno, en que se anudan cuerpo, ética y política. En palabras de Rose, «los regímenes de verdad de las ciencias de la vida han mutado y con estos cambios la biopolítica se ha convertido en ethopolítica» (2006: 45).

En esta nueva racionalidad de ejercicio de poder, la vida es desplegada en el campo de actividad política y legal a partir de una completa reformulación de su sentido y contenido. Ese cambio supone el advenimiento de una era que él denomina «Edad molecular». En ella, las herramientas de diagnóstico de ADN, la secuenciación computarizada de los genes, las distintas técnicas de intervención genética, etc., suponen que podemos al mismo tiempo descodificar, codificar y recodificar el material biológico. Y, a través de esas posibilidades, intervenir sobre nuestro cuerpo como nunca antes se había podido hacer. Semejante intervencionismo ha permitido, además, la creación de un poderoso vínculo entre biología y capital en tanto que la primera se convierte en información y circula

2. Para profundizar en esta temática desde la influencia de las neurociencias, Martín (2000). 
por distintas redes, bancos y sistemas de almacenamiento que se pueden poseer, comprar y vender como propiedad intelectual ${ }^{3}$.

Todo lo anterior tiene un corolario directo en cómo entendemos y gobernamos nuestros cuerpos. Las terapias genéticas y la nanotecnología permiten que estos sean entendidos menos en términos de fe, destino y accidente, y más como entidades en permanente perfeccionamiento, prevención de riesgo y voluntad de salud (Rose, 2006).

El resultado es que la relación ética que establecemos con nuestros cuerpos también se transforma. Los dilemas acerca de lo que somos, podemos hacer, esperamos ser o deberíamos conseguir alcanzan la dimensión molecular. En tal sentido, es nuestra propia corporalidad, su vida misma, y no solo nuestra conducta, la que se convierte en sujeto de lo que Foucault llamó «tecnologías del yo». La ethopolítica es el nombre de la nueva relación con nosotros mismos, que se define en términos de futuros abiertos y de continuo perfeccionamiento. A través de la contratación de seguros sanitarios privados, de una formación permanente, de una actividad asociativa con personas con los mismos problemas o patologías, de un cuidado particular del cuerpo, etc., el individuo asume como responsabilidad ética permanente el cuidado y perfeccionamiento de su cuerpo y salud.

Sin duda alguna, las aportaciones de Nikolas Rose en el diagnóstico crítico de la conformación de nuevas racionalidades políticas en nuestro presente son valiosas. Mas cabe preguntarse si la transformación molecular de la vida que describe este autor es la única manera en que esta se ha transformado en nuestra actualidad. Nuestra respuesta es: ¡no! En este artículo argüiremos que han aparecido discursos y prácticas que impactan en la noción de vida que manejamos pero que lo hacen de un modo distinto a como lo describe Rose ${ }^{4}$. Concretamente, sostendremos que la reciente preeminencia de los dispositivos de bioseguridad en la Unión Europea muestra que la vida está sufriendo otro tipo de reconceptualización. La definición molecular que establecen las ciencias biomédicas y genéticas es integrada en un dispositivo de inteligibilidad mayor que convierte lo biótico en una trayectoria o flujo de movimiento que alcanza dimensiones escalares variables y es rastreable y representable en todo momento.

Tal reconceptualización instala en el centro de la arena política un nuevo problema: el movimiento o motilidad de lo biótico. Su gestión y

3. Por ejemplo, desde otra perspectiva, se pueden analizar las relaciones establecidas entre biología y capital rastreando el comercio global de órganos que Vandana Shiva (2001) califica con el término de «biopiratería».

4. Desde otro enfoque, esta labor ha sido desplegada por autores como Giorgio Agamben o Didier Fassin. Ver, por ejemplo, Fassin (2003). 
administración supone la aparición de una nueva racionalidad de gobierno que hemos denominado cinepoder. Para ilustrar lo afirmado, primero revisaremos el papel que jugó el movimiento en la definición de la noción de biopolítica propuesta por Michel Foucault. Sostendremos que el problema ya estaba presente en su obra pero que se solventó convirtiéndolo en un resultado fenomenológico derivado de variables puramente biológicas y sociales. A continuación, presentaremos un estudio de caso sobre los dispositivos de bioseguridad de la Unión Europea que nos permitirá analizar el tipo de transformación que la vida experimenta en su interior, y examinar cómo emerge esa nueva razón de gobierno que supone el cinepoder.

\section{Una definición no canónica de biopolítica}

Uno de los principales legados del filósofo francés Michel Foucault es su noción de biopolítica ${ }^{5}$. La impronta del concepto se nota en algunas de las filosofías europeas más importantes del momento (Agamben, 1998; Hardt y Negri, 2005) o en la creación dentro del pensamiento social de un nuevo terreno de análisis centrado en la relación entre "gubernamentalidad» y genealogía del sujeto (Rose, 1999; Rose y Novas, 2004). La definición del término es bien conocida; en su formulación general hace referencia a la gestión o administración de la vida y, en una más específica, insiste en la constitución histórica de la vida como terreno de acción política que emerge de manera paralela y vinculada al auge del liberalismo. Junto a la idea de anatomopolítica, conformó el gran dispositivo histórico de transformación de las relaciones de poder que Foucault denominó biopoder.

No obstante, la correcta comprensión del concepto exige que se atienda a un elemento muy específico: la definición de población. La idea de población es tan importante para el filósofo francés que, de hecho, el curso que dicta en el Collège de France en 1978 lo titula Seguridad, territorio, población y lo dedica a analizar esta última como una de las principales condiciones que permiten la emergencia de la noción de biopolítica ${ }^{6}$ ¿¿Qué es exactamente la población para Foucault?

5. Como nos recuerda Roberto Expósito (2004), Foucault no es el primero en utilizar el concepto. Probablemente, el neologismo lo creó el sueco Rudolph Kjellen, quien también acuñó la expresión «geopolítica». No obstante, debe reconocerse que la reformulación foucaultiana es harto novedosa y responsable de la popularidad que el concepto exhibe en la actualidad en el pensamiento social.

6. El curso del año siguiente llevará el título de El nacimiento de la biopolítica (2007) y estará dedicado al examen detallado de esta técnica de poder. 
Pues diversas cosas al mismo tiempo. En primer lugar, un problema político. De hecho, el más llamativo en la Modernidad. En segundo, una producción histórica que se naturaliza rápidamente. La población es un objeto que se gesta entre finales del siglo XVII y todo el XVIII. A lo largo de esos años y gracias a las formulaciones y prácticas de los mercantilistas y fisiócratas, de los economistas de ese siglo, hablando más genéricamente, la población deja de presentarse como un conjunto de sujetos de derecho, un agrupamiento de voluntades sometidas que deben obedecer la voluntad del soberano por intermedio de los reglamentos, las leyes y los edictos, y se convierte en un conglomerado de procesos que es menester manejar en sus aspectos naturales. Según Foucault, la población se naturaliza y se convierte en un objeto técnico, que se puede gestionar políticamente atendiendo a unas variables que la determinan y que están más allá de la mera voluntad del soberano. Tales variables entran directamente en el terreno de la ciencia. Así, su análisis muestra cómo la población pasa a depender del clima, del entorno, de la circulación de riquezas, de costumbres y tradiciones, y, especialmente, de elementos de subsistencia: nacimientos y defunciones, enfermedades, epidemias, etc. En tercer lugar, la población constituye una técnica de gobierno. Foucault sostiene que ese nuevo objeto natural que es la población cambia las tecnologías de gobierno. Estas ya no pueden pasar por la mera obediencia de los súbditos a la voluntad del soberano, sino que deben operar trabajando sobre las variables que afectan al devenir lógico de la población (Foucault, 2006).

Por tanto, la población es un nuevo objeto o superficie de actividad política que tiene la cualidad de haber transformado las viejas técnicas de gobierno. Mas no resulta descabellado preguntarse: ¿gobierno de qué? Y la respuesta que ofrece Foucault es muy clara: gobierno de la multiplicidad de los individuos. La población, al igual que la disciplina, es un dispositivo para gestionar las multiplicidades, extraer fuerzas productivas de ellas y ponerlas a trabajar. En definitiva, es el terreno de juego sobre el que adquiere su forma y sentido la biopolítica.

Sin embargo, una lectura atenta de la definición que ofrece Foucault nos ofrece una sorpresa interesante: el movimiento es una pieza clave en tal concepto.

Foucault caracteriza históricamente a las poblaciones hablando de movimiento de riquezas o monetario, circulación a través de las fronteras, desplazamiento urbano; se recuerda la metáfora de la circulación de la sangre en el análisis social, y se insiste en la relevancia que adquiere en la Europa de la Modernidad la circulación, cada vez más acelerada, de 
verdades y personas ${ }^{7}$. Sin embargo, el tema, finalmente, se liquida convirtiendo la movilidad en una función del territorio y del medio. Con tal gesto, la acción importante para su gestión queda reducida a la que debe operar directamente sobre este o sobre la propia población (capacidad de desplazamiento, etc.) que regularán ciertos saberes estadísticos. En suma, Foucault trata el movimiento como una variable actual y de ejecución más que se suma a las vitales y biológicas que ya hemos mencionado en la conformación de los diferentes ángulos de la definición de biopolítica.

En los siguientes apartados ilustraremos cómo gracias a la emergencia de los dispositivos de bioseguridad el soslayado tema del movimiento vuelve a cobrar una relevancia fundamental. Tal es así, que argüiremos que en tales dispositivos se producen dos fenómenos interesantes. Por un lado, la propia noción de vida en la que se basó Foucault para conceptualizar la idea de biopolítica sufre una redefinición tan importante que la asimila al concepto de trayectoria ${ }^{8}$. Y, por otro, crece una preocupación por desplegar mecanismos de control y gestión de estas trayectorias. Al conjunto de tales mecanismos los hemos denominado cinepoder 9 .

\section{La emergencia de la bioseguridad como problema}

En las dos últimas décadas, la «bioseguridad» se ha convertido en un término relevante en el espacio político internacional, en las ciencias sociales y en el imaginario popular. En el primer ámbito encontramos multitud de instancias internacionales que han declarado que la bioseguridad delimita un espectro prioritario para la legislación e intervención. En ese sentido, se puede mencionar la declaración que hace la Unión Europea en el año 2002 (E.U., 2002) estableciendo que existen tres grandes campos de riesgo en los que sus países integrantes deben establecer protocolos de bioseguridad: a) amenaza terrorista, b) investigación en laboratorios y c) transmisión de vectores infecciosos. También merecen especial atención los documentos que ha elaborado la Organización Mundial de la Salud (WHO), estableciendo la posibilidad de aparición de riesgos en bioseguridad como una

7. En ese sentido, Foucault insiste en que por circulación no hay que entender únicamente la red material que permite la circulación de mercancías o personas, sino la circulación misma, es decir, el conjunto de los reglamentos, restricciones, límites o, por el contrario, facilidades y estímulos que permitirán el tránsito (Foucault, 2006).

8. A este respecto, para el análisis de la transición de las «sociedades disciplinarias» a las «sociedades de control», resulta indispensable tener en consideración las aportaciones de Deleuze (1995).

9. Cine es un prefijo griego que expresa la idea de movimiento. Para ser más precisos, deberíamos redactarlo como kinepoder, mas hemos optado por castellanizar el neologismo. 
necesidad prioritaria de alcance mundial (WHO, 2008a y 2008b). De manera similar, la Organización Mundial del Comercio (WTO) reconoce que la bioseguridad se ha tornado un tema fundamental en el concierto global en la medida en que el movimiento de especies, enfermedades y patógenos se ha incrementado con la aceleración que han experimentado las transacciones económicas (WTO, 2008). Y la Organización de las Naciones Unidas para la Alimentación y la Agricultura (FAO) también ha jugado un papel esencial en la promoción del concepto de bioseguridad enfatizando tanto las limitaciones que puede generar una legislación muy estricta en materia de bioseguridad para los países en vías de desarrollo como la necesidad de crear estrategias globales e integrales de bioseguridad (Unfao, 2007). Junto a estas instituciones se pueden mencionar otras muchas relacionadas con la defensa del medio ambiente y la preocupación ecológica. Por ejemplo, la International Union for the Conservation of Nature (IUCN, 2000) y la Convention on Biological Diversity (CBD, 2011) han desarrollado desde hace muchos años importantes protocolos y planes de actuación para prevenir riesgos de bioseguridad en ecosistemas tan específicos como ríos, embalses, etc.

En el segundo encontramos una serie de investigaciones y trabajos realizados recientemente que han conformado lo que se ha denominado «el campo de los estudios sobre bioseguridad» (Caduff, 2015; Lakoff y Collier, 2008). Este está atravesado por un numeroso grupo de corrientes y propuestas teóricas. Entre ellas, destacan los estudios sobre gobernanza y biopolítica (Braun, 2007; Collier y Lakoff, 2008; Cooper, 2006); la Sociología, que analiza cuestiones relacionadas con el riesgo, la incerteza y la indeterminación en situaciones de amenaza biológica (Donaldson, 2008; Hinchliffe, 2001; Fish, Austin, Christley, Haygarth, Heathwaite, Latham, Medd, Mort, Oliver, Pickup, Wastling y Wynne, 2011); la Sociología del conocimiento científico, que examina la producción de redes, materialidad, circulación y movilidad (Ali y Keil, 2008; Barker, 2010; Clark, 2002; Wallace, 2009); el pensamiento social, que investiga procesos de creación de fronteras y límites espaciales a partir de riesgos bióticos (Mather y Marshall, 2011; Tomlison y Potter, 2010); y los estudios geopolíticos, interesados por la generación de procesos de globalización y producción de relaciones de desigualdad entre países (French, 2009; Sparkle, 2009).

El tercer ámbito en el que la bioseguridad ha adquirido una importancia clave es el imaginario popular. En los últimos años han proliferado imágenes en los medios de comunicación, literatura y cine sobre amenazas biológicas, la velocidad de su transmisión y sus efectos devastadores sobre los grupos humanos, las consecuencias para la vida humana de las 
relaciones entre diferentes especies vivas, amenazas medioambientales, etc. Este material de entretenimiento ${ }^{10}$ se suma a las prácticas profilácticas que diversas pandemias (especialmente las de gripe) han popularizado, y a la información y campañas de pedagogía que grupos y colectivos de activistas ecologistas han realizado sobre alimentos transgénicos, vacunas, etc. Algunos análisis han denominado al mencionado imaginario «nueva cultura del Apocalipsis» (Van Loon, 2002). Y más allá de lo llamativo de esta etiqueta, lo que resulta interesante es la aparición en todo ese material de nuevas categorías y metáforas populares para entender: a) la naturaleza y nuestra relación con el medio ambiente; b) las enfermedades infecciosas y su impacto en el grupo humano; c) la seguridad y su papel en la organización de la sociedad; o d) las relaciones entre especies vivas.

\section{Cinepoder y bioseguridad}

\subsection{Metodología y recolección de datos}

Nuestra investigación es un estudio de caso que ha durado dos años sobre el problema de la bioseguridad en la Unión Europea. Como tal estudio, hemos recopilado todo tipo de material empírico: información proveniente de los medios de comunicación (noticias periodísticas, comunicados, imágenes...), protocolos y material obtenido en centros de salud y hospitales, entrevistas individuales con expertos en bioseguridad animal y humana, literatura y cine, y documentos oficiales emitidos por diferentes instancias de la Unión Europea. El análisis de los mismos y su articulación obedece al esquema de trabajo que Geertz (1973) denominó descripción densa. Es decir, ofrecemos un relato que desgrana tramas de significado a través de la relación que se establece entre los distintos elementos empíricos y que está guiada por nuestra pregunta de análisis. En ese sentido, a continuación presentamos solo una parte específica de tal análisis. Concretamente, la que hace referencia a un tema soslayado sistemáticamente por los estudios sobre bioseguridad. Nos referimos al hecho de que estos han insistido en las profundas transformaciones que los discursos, imágenes, prácticas y dispositivos vinculados con las amenazas biológicas suponen para la noción de seguridad. Sin embargo, han obviado que esa profunda transformación también afecta al prefijo de la palabra «bioseguridad». Es decir, a

10. Véase, por ejemplo, la película Contagio de Steven Soderbergh. O series como: In the Flesh, de Dominic Mitchell, Containmment, de Julie Plec, así como libros como Inferno de Dan Brown como última publicación. 
la propia noción de vida o lo biótico. Y esa transformación anuncia un profundo cambio en la racionalidad de poder que supone la bioseguridad para nuestras sociedades contemporáneas.

\subsection{La vida es motilidad}

Curiosamente, el material mencionado en el apartado anterior, a pesar de su diferente procedencia y formato, detenta un denominador común: el problema del movimiento. Su punto de partida es la definición de una situación presente en la que existe una gran movilidad global de mercancías, animales, semillas, humanos, virus y bacterias ${ }^{11}$. Ese movimiento a priori deseable genera una serie de consecuencias importantes. Una de ellas es que deslocaliza tales entidades, las relocaliza en espacios inéditos y, además, potencia la aparición de relaciones entre elementos que sin las mencionadas condiciones de movilidad jamás habrían entrado en relación.

Antes entendimos la vida más como un hecho mucho más biológico-médico, en cierta forma cerrada. La nueva forma de trabajar con la enfermedad nos ha hecho pensar sobre muchos otros factores, factores logísticos y como en el caso del ébola, factores sociales (Enric Trillas. Epidemólogo. Hospital Clinic de Barcelona).

Esto conforma el terreno de definición de la bioseguridad e impele a gobiernos locales y entidades internacionales a implementar medidas de intervención en la línea de limitar tales riesgos. No obstante, los citados documentos muestran algo más: la completa redefinición de la vida a partir de tres características vinculadas con la motilidad.

En primer lugar, observamos que ha cambiado la estructura clásica del movimiento. Si este se ha asociado tradicionalmente a personas y bienes, ahora, por un lado, se mueven vectores, virus, bacterias y, por otro, se mueve el riesgo. En ese sentido, los regímenes de bioseguridad convierten en su centro de interés la naturaleza de lo que se mueve en nuestras redes de tránsito global. Tal cosa se observa con claridad en los siguientes extractos:

Considerando que, tan pronto como se declare un brote de esta enfermedad, es necesario evitar su propagación controlando de modo estricto los movimientos de animales y la utilización de productos que puedan estar contami-

11. En este sentido, no está de más recordar la inextricable relación establecida entre globalización y flujos. Consultar, por ejemplo, Appadurai (2001). 
nados, recurriendo, en su caso, a la vacunación (Directiva 92/66/CEE del consejo de 14 de julio de 1992, consideraciones).

Además de lo establecido por la legislación comunitaria en materia de notificación de focos de enfermedades animales, los Estados miembros comunicarán a la Comisión, de conformidad con el anexo II, cualquier caso de influenza aviar, confirmado por las autoridades competentes, en mataderos, medios de transporte, puestos fronterizos de control y otros puntos de las fronteras comunitarias, así como en instalaciones y centros de cuarentena que operan de conformidad con la legislación comunitaria en materia de importación de aves de corral u otras aves cautivas (Directiva 2005/94/CE del consejo de 20 de diciembre de 2005 , artículo 2).

En segundo lugar, aparece la velocidad como un determinante fundamental en la preocupación por el movimiento de lo biótico. Si leemos atentamente el siguiente extracto observaremos que el Libro Verde de la Unión Europea considera que debe existir un sistema y estado de alerta permanente porque los vectores infecciosos evolucionan a una velocidad hasta ahora desconocida:

Los laboratorios de biología móviles y las pruebas «a pie de granja», con el apoyo de conocimientos especializados, pueden ser necesarios para la intervención e identificación rápida en cualquier lugar de la Unión Europea o a nivel internacional, de conformidad con las normas del Grupo Australia y el Reglamento (CE) n. ${ }^{\circ}$ 1334/2000 sobre productos y tecnología de doble uso. La movilidad, la versatilidad y la flexibilidad son elementos importantes para la prevención de catástrofes de tipo biológico (Libro Verde sobre la Preparación frente a Amenazas Biológicas, p. 16) ${ }^{12}$.

La epizootia de fiebre aftosa que se produjo en ciertos Estados miembros en 2001 demostró que, debido a lo intenso del movimiento y del comercio de animales sensibles a esta enfermedad, un foco puede tomar rápidamente proporciones de epizootia, causando perturbaciones a tal escala que se vea muy reducida la rentabilidad de la ganadería de animales de especies sensibles y de otros sectores de la economía rural, y haciendo asimismo necesaria la movilización de importantes recursos económicos para compensar a los ganaderos y la aplicación de medidas de lucha contra la fiebre aftosa ${ }^{13}$.

12. Por otra parte, sobre el paradigma de la «flexibilidad», resulta de interés la obra de Martin (1994).

13. Directiva del Consejo 2003/85/CE, de 29 de septiembre de 2003, consideraciones. 
Algunos de los protocolos que hemos estudiado proponen estrategias para mejorar la velocidad de detección y alerta rápida de las amenazas. Dentro de las proposiciones destaca el cultivo de muestras, generalmente en esputo (cultivo de Lowenstein-Jensen, o agar de Midlebrook). Es una técnica mucho más sensible que la baciloscopia, pero es un método lento, pudiendo no observarse crecimiento hasta las 6-8 semanas desde la siembra, aunque existen otros métodos de cultivo mucho más rápidos (radiométricos y no radiométricos) pero no generalizados en todos los laboratorios ${ }^{14}$.

Y, por último, se desarrollan sistemas de representación cuyo interés es consignar en un golpe de vista tanto los vectores de movimiento como su velocidad. Un buen ejemplo es el siguiente gráfico que recoge tanto flujos de migraciones como sus intensidades:

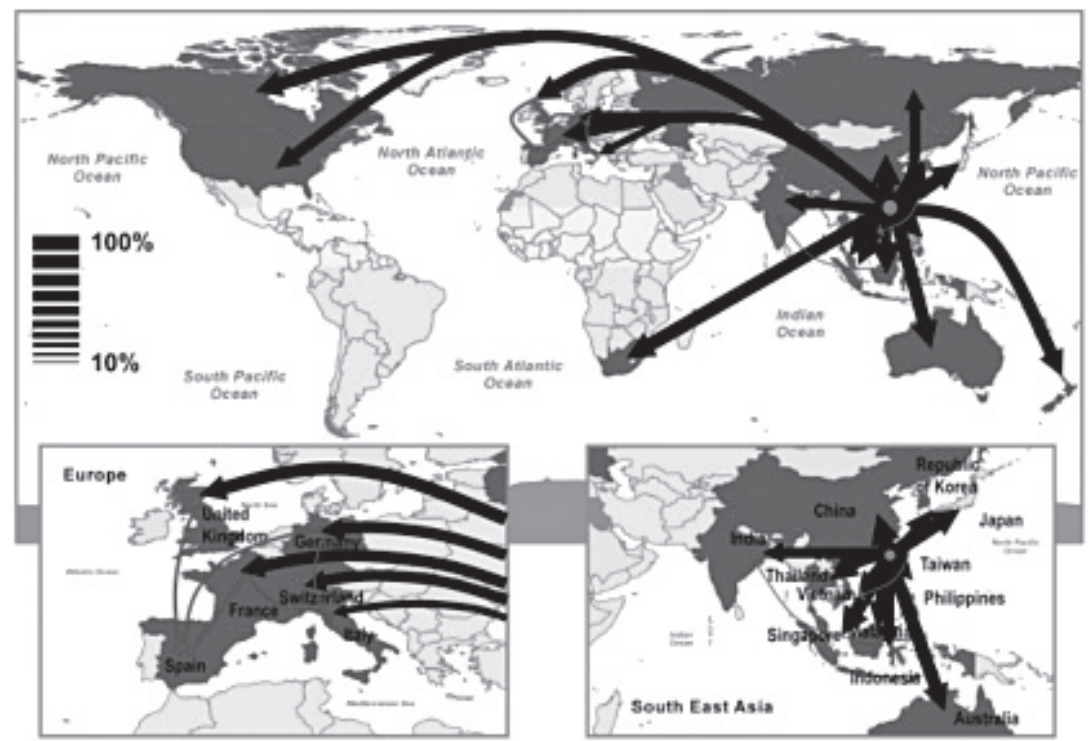

Figura 1. Predictibilidad y vías epidémicas en brotes globales de enfermedades infecciosas: El estudio de caso del SARS. Fuente: BioMedSearch.com.

14. Protocolos de vigilancia sanitaria específica. Agentes biológicos. Comisión de Salud Pública. Consejo Interterritorial del Sistema Nacional de Salud. 


\subsection{La vida se despliega en diferentes escalas}

Pero, además, la vida es conceptualizada como un fenómeno multiescalar. Permítasenos pedir al lector que examine atentamente estos extractos de un proyecto sobre gripe y un Libro Verde sobre "preparedness» (protocolo de acción futura), respectivamente:

El modelo directriz estará disponible para los actores clave, incluidas las autoridades de salud pública, autoridades regionales y municipales, líderes municipales, expertos en comunicación de enfermedades, agrónomos y veterinarios, que se espera que lo usen en diseñar sus campañas para la prevención de la gripe aviar. (Influenza research, EU funded projects 20012007 , p. 91$)^{15}$.

A fin de mejorar la capacidad de la UE para prevenir, responder y recuperarse de un accidente biológico o de un acto delictivo intencionado, la coherencia de las acciones emprendidas en las diferentes políticas exige consultar a todos los participantes relevantes en los Estados miembros y en la UE, a saber, autoridades nacionales responsables de la respuesta y la prevención de riesgos, la salud pública (humana, animal y vegetal), las aduanas, la protección civil, las autoridades policiales, el ejército, la bioindustria, la comunidad sanitaria y epidemiológica, las instituciones académicas y los organismos de investigación biológica (Green Paper on Bio-preparedness, presented by the Commission, p. 2).

Cuatro elementos llaman inmediatamente la atención en las anteriores líneas. El primero es la tremenda mezcla de actores que aparecen implicados en el tratamiento de la bioseguridad. Diferentes instituciones, públicas y privadas, sectores económicos o entidades políticas y ciudadanas son advertidas de la necesidad de su coordinación y acción concertada para prevenir el riesgo biológico. El segundo hace referencia a la terrible diferencia que hay en el tamaño o en las escalas de las entidades emplazadas a la acción anterior. Unidades policiales, Estados nacionales, continentes como Europa, empresas, poblaciones de animales, entidades sanitarias o ciencias epidemiológicas conviven en sus páginas en son de paz e interaccionan gracias a la noción de amenaza biológica. El tercero muestra que la seguridad aparece como el vector que cruza todas esas escalas y las teje en una ordenación común. Sin embargo, este vector no tiene valor per se, es simplemente una respuesta a la ame-

15. Para indagar en esta nueva arquitectura supranacional de instituciones de poder, ver Sharma y Gupta (2006). 
naza que constituye la vida entendida como relación interespecie y como algo móvil. Por tanto, es la vida misma la que aparece constituida como un vector multiescalar que solo es aprehensible si se le proyecta sobre todas esas diferentes escalas. Por primera vez en la historia, la vida se define contra un escenario global y se plantea la problemática que supone su aprehensión de manera general. Un virus ya no es un elemento microscópico que reside en una célula. Ahora es un vector que atraviesa cuerpos, colectivos, poblaciones, países, continentes, sectores económicos, políticos, y prácticas o rutinas tanto novedosas como milenarias.

No entendemos más el virus exclusivamente como un fenómeno local pero principalmente en su potencial de expandirse. El virus es local pero simultáneamente en muchos lugares a donde aún no ha llegado (Enric Trillas. Epidemólogo. Hospital Clinic de Barcelona).

Por último, sorprende el papel doble que juega el futuro en la articulación de todas estas escalas y entidades. Por un lado, su sombra se proyecta sobre el presente y lo impele a organizarse de una manera concreta: desplegando dispositivos de protección. Por otro, su constitución como proyección está ligado a la comprensión de la vida como amenaza invariante. Es decir, dado que la vida encierra en su interior un riesgo latente, el futuro adquiere el valor de riesgo probable y constante en el porvenir. Por primera vez, nos enfrentamos al desafío de aprehender y definir un fenómeno que se considera deslocalizado y omnipresente en múltiples dimensiones y tamaños.

\subsection{La motilidad de la vida es representable}

Como hemos visto en el vínculo que se establece entre vida y movimiento, los discursos y prácticas sobre bioseguridad expresan claramente la necesidad de representar lo biótico. Su motilidad y amenaza aparecen como las exigencias pertinentes de este imperativo. Y, de ese modo, la bioseguridad se constituye en realidad en un juego de declaraciones y propuestas que siempre se acompañan y articulan con imágenes sobre vectores infecciosos y mapas con posibles recorridos y traslaciones de los mismos. Un buen ejemplo sería el siguiente: 


\section{Get Vaccinated: Prevent and Stop Measles Outbreaks}

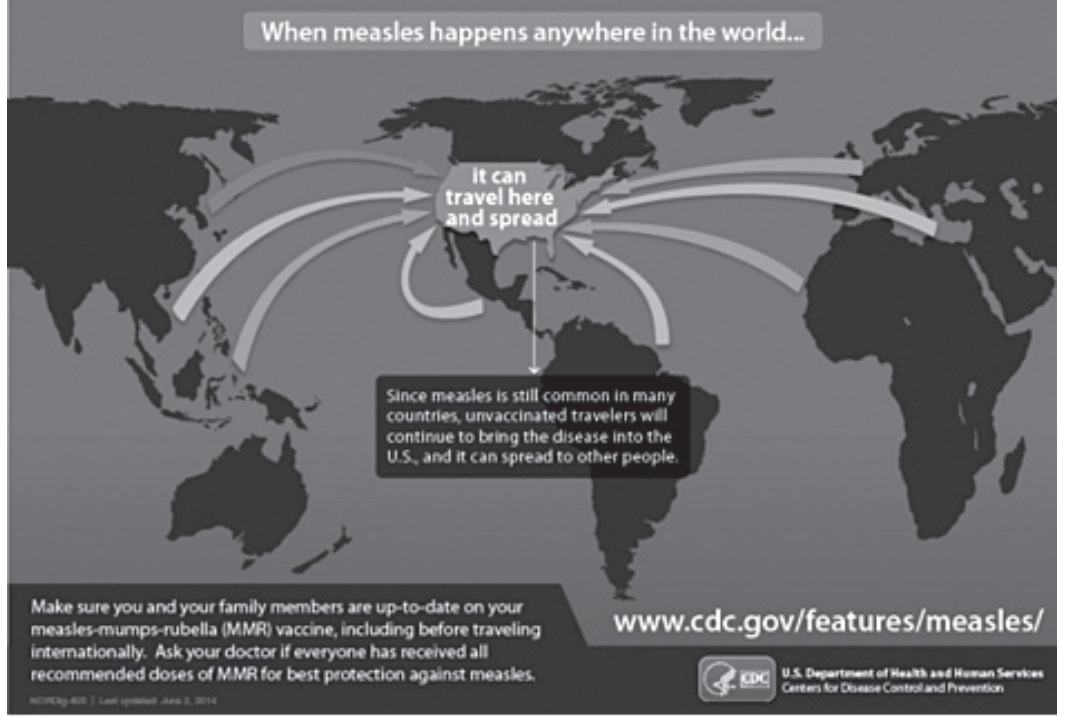

Figura 2. Infografía sobre la importación del sarampión en Estados Unidos. Fuente: Centers for Disease Control and Prevention (CDC).

Como han señalado algunos trabajos (Tirado y Cañada, 2011; Tirado, Gómez y Rocamora, 2014) este material crea varios efectos:

1) Ofrece visibilidad a los vectores contagiosos desde una perspectiva geográfica antes que médica o estadística. Esto localiza al mencionado vector en una escala global que lo presenta como un problema que afecta a todo el mundo, en cualquier país, y en cualquier posible momento.

2) Genera un sentido de homogeneidad en el desarrollo y características del vector. Lo que ocurre en Estados Unidos es similar a lo que puede ocurrir en España o Chile. Por lo tanto, se crea la impresión de que el fenómeno es comparable y equiparable en todos los lugares en los que puede manifestarse o aparecer.

3) Promueve el sentimiento de que podemos ver, seguir y rastrear el vector. Es decir, no puede esconderse en ningún lugar del planeta.

4) Finalmente, se genera la impresión de que el problema puede ser manejado y podemos intervenir sobre él.

La representación de la vida bajo estas formas la convierte en algo uniforme y comparable. Y como señalan diversos autores (Barry, 2001), la uniformidad y la comparabilidad que producen diversos operadores so- 
cio-técnicos crea un plano en el que los objetos, las personas y las acciones se tornan absolutamente comparables, sufren y producen los mismos efectos, son afectadas por las mismas causas, adquieren las mismas propiedades y son susceptibles de diferentes tipos de intervención, porque se convierten únicamente en factores de un potencial de la vida y la enfermedad.

Esta vida que se mueve, se articula en diferentes escalas y es representable, exige el desarrollo de múltiples prácticas locales y globales de gestión. Así, en los últimos años han proliferado las redes de vigilancia. Estas incluyen los denominados «Early Warning Systems», cuyo objetivo es identificar y contener brotes antes de que amenacen la seguridad de los Estados o del comercio mundial. Y, por supuesto, destacan las redes internacionales como Gphin (The Global Public Health Intelligence Network), una herramienta multilingüística de alerta temprana que opera a través de Internet y que continuamente revisa fuentes globales de información como websites, comunidades de radio o televisión, etc. O como ProMED, una red similar pero más extensa, ya que suma informes sobre brotes o infecciones entre animales y plantas. ProMED, por ejemplo, recoge informes de suscriptores y voluntarios de todo el mundo. El objetivo de estas redes globales de vigilancia es un examen global, sin límites, de los movimientos de vectores infecciosos y su impacto en la geografía local. Todos los sistemas anteriores están conectados con redes de laboratorios globales a los que envían puntualmente información que permite la elaboración de diagnósticos tempranos y el despliegue de propuestas de intervención para los Estados nacionales.

Como hemos señalado, los regímenes de bioseguridad que desde hace años se vienen desplegando en los países de la Unión Europea son operativos y adquieren su inteligibilidad sobre la base de una reconceptualización de nuestra comprensión de la vida. Esta aparece como un fenómeno vinculado intrínsecamente a la motilidad, que se despliega y articula al unísono en diferentes escalas y que esencialmente es representable. Desde nuestro punto de vista, tal reconceptualización anuncia una transformación más profunda que la que supone la definición del propio fenómeno biótico: se conforma, en ese sentido, un cambio de las relaciones de biopoder y comienza a esbozarse un nuevo dispositivo de creación de cursos de acción y gestión de la vida que hemos denominado "cinepoder».

\section{Del biopoder al cinepoder}

La noción de biopolítica señala un período histórico. Uno en el que la vida y lo viviente se convierten en el terreno de juego de las luchas políticas y las estrategias económicas. Como hemos señalado, en ese período el 
principal problema de gobierno fue la gestión de la multiplicidad de los individuos. La bioseguridad, que aparentemente está concernida por la misma cuestión, delimita, no obstante, un conjunto de prácticas y transformaciones que señalan hacia un desplazamiento en esa preocupación. La actividad de instituciones, normas y juegos de verdad que impactaban directamente sobre nuestros cuerpos como máquinas y como especie y constituían poblaciones, deja paso a prácticas, recursos y tecnologías que pretenden gestionar la multiplicidad del movimiento que genera una vida que es conceptualizada básicamente como trayectoria.

Como hemos visto en el anterior apartado, la bioseguridad ya no opera a partir de variables biológicas o naturales que podrían conformar poblaciones. Al contrario, ofrece un conocimiento que se caracteriza por los siguientes rasgos. En primer lugar, se elabora información y mensajes que son muy visuales, accesibles y que buscan llegar con claridad al mayor número posibles de receptores. La bioseguridad se presenta como un conocimiento para especialistas y legos, es decir, para un gran público. En segundo lugar, la vida es conceptualizada como una trayectoria que atraviesa en su flujo determinadas zonas geográficas y es capaz de mezclarse con otros elementos vivos, con más vida. Lo biótico es concebido en términos de circulación e intercambio. Semejante concepción tiene cierta historia en el pensamiento social. Los historiadores han documentado ampliamente el desarrollo de ciertas plagas y epidemias y han tomado en consideración los ejercicios de cuarentena que buscaban aislar cuerpos y evitar contagios (Watts, 1999). Sin embargo, con la bioseguridad asistimos a la aparición de dos nuevos elementos. Uno es que el cuerpo ya no es base para comprender el fenómeno de contagio y por tanto sus dimensiones no definen poblaciones. Ahora, el vector infeccioso estructura el fenómeno de contagio, que es conceptualizado como movimiento, y la representación de su flujo crea públicos de personas que virtualmente pueden ser afectadas. Otro hace referencia a la escala del movimiento; este se mueve de lo local a lo global y articula ambas dimensiones en un mismo conjunto de actividad. Por último, los ejercicios de salud pública ya no se implementan, al menos no exclusivamente, a partir de los cuerpos de los afectados, sino del mencionado movimiento del vector infeccioso. Por tanto, es el movimiento o capacidad de motilidad de este la que determina la gestión que se realiza de la vida. Y a esta nueva gestión la hemos denominado cinepoder.

La bioseguridad convierte en un conocimiento accesible para un gran público los desarrollos de la biología molecular en conjunción con la virología y la inmunología. Estas nos ofrecen una geografía molecular de la vida en términos de redes, trayectorias, movimientos e intercambios. Algunos autores (Braun, 2007) han señalado que la bioseguridad nos 
pone sobre la pista de cómo la globalización ha aprehendido el cuerpo molecular. Es decir, esta estaría señalando un conjunto de respuestas políticas en la Era de la Globalización al desafío de un cuerpo que está abierto a la influencia de otros cuerpos. Sin embargo, nuestra investigación muestra que la bioseguridad es mucho más que el programa de actividad político sobre el cuerpo desplegado por la globalización. Es una nueva racionalidad que redefine la propia noción de vida y la despliega en un nuevo problema: su movimiento. Y frente a ese problema, se conforma un nuevo tipo de gestión centrado en la representación e intervención sobre los posibles flujos de motilidad.

La bioseguridad nos pone sobre la pista de otro elemento interesante: muestra que el movimiento no es en absoluto un dato evidente. Constituye un logro, una realización que requiere de una infraestructura de saberes, discursos y prácticas que lo torna real y factible. Desde hace una década, las discusiones sobre la movilidad se han vuelto frecuentes en las ciencias sociales y normalmente se basan en varias asunciones que se manejan de manera completamente acrítica. Concretamente, se presupone que el movimiento per se genera cambio, que es autoevidente, y que la característica principal de nuestro presente es la enorme capacidad de movilidad que tenemos a nuestro alcance. Ante este estado de cosas resulta imprescindible preguntarnos qué cuenta actualmente como movimiento y qué no. Mientras que el movimiento de miles de turistas a través de los circuitos internacionales preparados para tal evento es completamente legítimo, la circulación de las últimas familias nómadas de tuaregs a través de los países que circundan el Sahara se considera ilegítimo, está prohibida y perseguida. Frente a la imagen de un movimiento claro, evidente y etéreo que ofrecen los actuales relatos sobre la movilidad (Urry, 2007), debemos asumir que nos enfrentamos a una multitud de prácticas que establecen las condiciones de lo que se considerará movimiento o no, movilidad legítima o ilegítima, que nos dotan, o no, con nuestra potencial motilidad ${ }^{16}$.

En suma, la movilidad constituye un logro precario que exige un esfuerzo y el establecimiento de un conjunto de prácticas y definiciones que lo permiten o lo deniegan. Pues bien, la bioseguridad hace exactamente ese trabajo: instaura regímenes de motilidad para la vida y los representa (Tirado, Gálvez y Castillo, 2012). Y la consecuencia de este hecho, aunque no demasiado visible, es tremendamente relevante, pues supone la transformación de todo un orden político, su representación y la instauración de mecanismos para intervenir sobre él. La biopolítica no desaparece, por

16. Bajo esta grilla de lectura, resulta de enorme relevancia tener en consideración la actual crisis de refugiados a la que se enfrenta Europa. Por otra parte, desde una perspectiva analítica respecto a la movilidad, de gran interés resulta el trabajo de Marc Augé (2007). 
supuesto, pero su acción queda subsumida en el proceso, aparentemente más simple, de establecer trayectorias, de aunar biología y movimiento, y determinar las condiciones de su gestión. La descripción y análisis de tal proceso constituye todo un desafío de futuro para las ciencias sociales.

\section{Conclusiones}

En los últimos años, diversos trabajos han coincidido en señalar que las propuestas foucaultianas sobre el biopoder necesitan ser revisadas. Entre los diversos argumentos que se han presentado para tal reformulación, destaca el que se centra en la emergencia de las ciencias biomédicas y la reconceptualización que suponen de la noción de vida. Nosotros, sin embargo, hemos planteado que esa no es la única transformación que el concepto está sufriendo en nuestro presente. Los dispositivos de bioseguridad que se están popularizando en nuestra vida cotidiana realizan un ejercicio similar. La única diferencia con el planteado por autores como Nikolas Rose es que la vida no se moleculariza, sino que se convierte en una trayectoria, que se despliega articulando distintas escalas y que es, fundamentalmente, algo representable a través de mapas, diagramas, etc. Esa transformación supone una reconfiguración del centro de actividad de las relaciones de poder. La bioseguridad implementa el movimiento como objeto de gestión y de interés político. A tal tipo de gestión la hemos denominado cinepoder. Este no sustituye a la acción biopolítica, la subsume, y tampoco es una alternativa a la ethopolítica que formula Rose. Todo lo contrario, complementa su actuación. Si esta segunda convierte nuestros cuerpos en un imperativo de salud para el individuo, la primera se ocupa de gestionar el movimiento de estos y sus componentes en una escala total y global.

\section{Referencias bibliográficas}

Agamben, G. (1998): Homo Sacer. El poder soberano y la nuda vida. Valencia: Pre-Textos. Ali, H. y Keil, R. (Eds.) (2008). Networked disease: emerging infections in the global city. West Sussex: Wiley-Blackwell.

Amar,G. (2011). Homo Mobilis. La nueva era de la Movilidad. Buenos Aires: La Crucija. Appadurai, A. (2001). Grassroots Globalization and the Research Imagination. En Globalization. A. Appadurai, Ed. Durham: Duke University Press. Augé. M. (2007). Por una antropología de la movilidad. Barcelona: Gedisa 
Barker, K. (2010). Biosecure citizenship: politicising symbiotic associations and the construction of biological threat. Transactions of the Association of British Geographers, 35: 350-63.

Barry, A. (2001). Political machines. Governing a technological society. London: Athlone Press.

Braun, B. (2007). Biopolitics and the molecularization of life. Cultural Geographies, 14: 6-28.

Caduff, C. (2015). The Pandemic Perhaps. Dramatic Events in a Public Culture of Danger. Oakland: University of California Press.

CBD (2011). Considerations for Implementing International Standards and Codes of Conduct in National Invasive Alien Species Strategies and Plans. Secretariat of the Convention on Biological Diversity, United Nations Environment Programme. Montreal.

Clark, N. (2002). The demon-seed: bioinvasion as the unsettling of environmental cosmopolitanism. Theory, Culture and Society, 19: 101-25.

Collier, S. y Lakoff, A. (2008). The problem of securing health. En Biosecurity interventions: global health and security in question. A. Lakoff y S.J. Collier, Eds. New York: Columbia University Press.

Collier, S. y Lakoff, A. (2014). Vital Systems Security: Reflexive Biopolitics and the Government of Emergency. Theory, Culture \& Society, 4(1): 1-33.

Cooper, M. (2006). Pre-empting emergence: the biological turn in the war on terror. Theory, Culture and Society, 23(4): 113-35.

Das, V. y Poole, D. (2004). State and Its Margins. Comparative Ethnographies. En Anthropology in the Margins of the State. V. Das y D. Poole, Eds. Santa Fe: School of American Research.

Deleuze, G. (1995). Post-scriptum sobre las sociedades de control. En Conversaciones. Valencia: Pre-Textos.

Donaldson, A. (2008). Biosecurity after the event: risk politics and animal disease. Environment and Planning A, 40: 1552-67.

Expósito, R. (2004). Bíos. Biopolítica y filosofía. Buenos Aires: Amorrortu.

Fassin, D. (2003). Gobernar por los cuerpos. Políticas de reconocimiento hacia los pobres y los inmigrantes en Francia. Cuadernos de Antropología Social, 17: 49-78.

Fish, R.; Austin, Z.; Christley, R.; Haygarth, P.M.; Heathwaite, A.L.; Heathwaite, L.A.; Latham, S.; Medd, W.; Mort, M.; Oliver, D.M.; Pickup, R.; Wastling, J.M. y Wynne, B. (2011). Uncertainties in the governance of animal disease: an interdisciplinary framework for analysis. Philosophical Transactions Of The Royal Society Of London Series B - Biological Sciences, 366(1573): 2023-34.

Foucault, M. (2006). Seguridad, territorio, población. México: Fondo de Cultura Económica.

Foucault, M. (2007). El nacimiento de la biopolítica. México: Fondo de Cultura Económica. French, M.A. (2009). Women of war-time fabrics: the globalization of public health surveillance. Surveillance and Society, 6(2): 101-15.

Geertz, C. (1973). The interpretation of cultures. New York: Basic Books. 
Hinchliffe, S. (2001). Indeterminacy in-decisions: science, policy and politics in the BSE (bovine spongiform encephalopathy) crisis. Transactions of the Institute of British Geographers, 26: 184-204.

Hinchliffe, S. y Lavau, S. (2013). Differentiated circuits: the ecologies of knowing and securing life. Environment and Planning D: Society and Space, 31: 259-274.

IUCN (2000). Guidelines for the Prevention of Biodiversity Loss Caused by Alien Invasive Species. Glan: Switzerland.

Lakoff, A. y Collier, S. (2008). Biosecurity interventions: global health and security in question. New York: Columbia University Press.

Martín (2000). Mind-body Problems. American Ethnologist, 27(3): 569-590.

Martin, E. (1994). Flexible Bodies. Tracking immunity in American culture. From the days of Polio to the age of AIDS. Boston: Beacon Press.

Mather, C. y Marshall, A. (2011). Biosecurity's unruly spaces. The Geographical Journal, 177(4): 300-310.

Negri, A. y Hardt, M. (2005). Imperio. Barcelona: Paidós Surcos.

Rose, N. (1989). Governing the Soul: The Shaping of the Private Self. New York: Routledge.

Rose, N. (1996). Inventing Ourselves: Psychology, Power, and Personhood. New York: Cambridge University Press.

Rose, N. (2006). The Politics of Life Itself. Oxford: Princeton University Press.

Rose, N. y Abi-Rached (2013). Neuro: The New Brain Sciences and the Management of the Mind. Princeton: Princeton University Press.

Rose, N. y Novas, C. (2004). Biological Citizanship. En Companion to Global Anthropology. A. Ong. y S. Collier, Eds. Oxford: Blackwell.

Sharma, A. y Gupta, A. (Eds.) (2006). The Anthropology of the State. A reader. Oxford: Blackwell.

Sparkle, M. (2009). On denationalization as neoliberalisation: biopolitics, class interest and the incompleteness of citizenship. Political Power and Social Theory, 20: 287-300.

Tirado, F. y Cañada, J. (2011). Epidemias. Un nuevo objeto sociotécnico. Convergencia. Revista de Ciencias Sociales, 18: 133-156.

Tirado, F.; Gálvez, A. y Castillo, J. (2012) Movimiento y regímenes de vitalidad. La nueva organización de la vida en la biomedicina. Política y Sociedad, 49(3): 571-590.

Tirado, F.; Gomez, A. y Rocamora, V. (2014). The Global Condition of Epidemics: Panoramas in A (H1N1) Influenza and their Consequences for One World One Health Programme. Social Science and Medicine.

Tomlison, I. y Potter, C. (2010). Too Little, too late? science, policy and Dutch elm disease in the UK. Journal of Historical Geography, 36(2): 121-31.

Unfao (2007). FAO biosecurity toolkit. Roma: FAO.

Urry, J. (2007). Mobilities. Cambridge: Polity Press.

Van Loon, J. (2002). Risk and Technological Culture. London: Routledge.

Wahlberg, A. y Rose, N. (2015) The Governmentalization of Living: Calculating Global Health. Economy and Society, Vol. 44(1): 60-90.

Watts, J. (1999). Smail Worlds. The dynamics of networks between order and randomness. New Jersey: Princeton University Press. 
World Health Organization (2008a). International health regulations: guidance for national policy-makers and partners'. En www.who.int/ihr/lyon/WHO_CDS_EPR_ IHR_2007_2EN.pdf

World Health Organization (2008b). Communicable disease alert and response for mass gatherings'. En www.who.int/ihr/lyon/WHO_HSE_EPR_2008_8c.pdf

WTO (2008).https://www.wto.org/english/res_e/booksp_e/anrep_e/world_trade_report08_e.pdf

\section{Fuentes primarias}

Entrevista a Enric Trillas. Epidemólogo del Hospital Clinic de Barcelona. Pobics (2015) 